\title{
ANTEROLATERAL APPROACHES FOR PROXIMAL HUMERAL OSTEOSYNTHESIS: A SYSTEMATIC REVIEW
}

\author{
VIAS DE ACESSO ANTEROLATERAIS PARA OSTEOSSÍNTESE DO \\ ÚMERO PROXIMAL: UMA REVISÃO SISTEMÁTICA
}

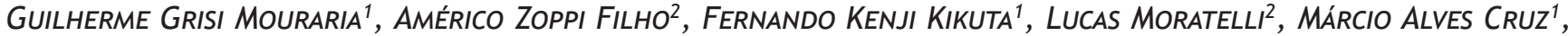 \\ MAURICIO ETCHEBEHERE ${ }^{2}$
}

1. Shoulder and Elbow Group, Orthopedic and Trauma Department, Faculdade de Ciências Médicas, Universidade Estadual de Campinas (UNICAMP), Campinas, SP, Brazil. 2. Orthopedics and Traumatology Department, Faculdade de Ciências Médicas, Universidade Estadual de Campinas (UNICAMP), Campinas, SP, Brazil.

\begin{abstract}
Objective: Anterolateral approaches for proximal humerus osteosynthesis have great advantages because they allow direct exposure of the lateral aspect of the humerus without the muscular retraction seen in the deltopectoral approach. However, much resistance is found among surgeons due to the potential risk of iatrogenic injury to the axillary nerve. To identify the incidence of axillary nerve iatrogenic lesions and evaluate the functional results of proximal humerus osteosynthesis with locking plates using anterolateral approaches. Methods: The literature review followed the PRISMA protocol. Results: A total of 23 articles were selected from 786 patients submitted to anterolateral approaches. Three cases $(0.38 \%)$ of iatrogenic axillary nerve lesions were confirmed. The results of the functional tests were similar to those of the deltopectoral approach. Conclusion: Anterolateral approaches are a viable and safe alternative for proximal humerus osteosynthesis with locking plate. Subacromial impingement was the most frequent complication. Level of Evidence II, Systematic Review.
\end{abstract}

Keywords: Humeral Fractures, Surgery, Complications, Osteosynthesis.

\section{RESUMO}

Objetivo: As vias de acesso anterolaterais para a osteossintese do úmero proximal permitem a exposição direta do aspecto lateral do úmero sem necessitar das retrações musculares da via deltopeitoral. Contudo, há grande preocupação com a possibilidade de lesão iatrogênica do nervo axilar e consequente piora no resultado funcional pós-operatório. Identificar a incidência de lesões iatrogênicas do nervo axilar e avaliar os resultados funcionais da osteossintese do úmero proximal com placas bloqueadas, utilizando as vias anterolaterais. Métodos: Revisão da literatura seguindo o protocolo PRISMA. Resultados: Foram selecionados 23 artigos do total de 786 indivíduos submetidos às vias de acesso anterolaterais. Foram confirmados 3 casos (0,38\%) de lesões iatrogênicas do nervo axilar. Os resultados dos testes funcionais foram semelhantes aos da via deltopeitoral. Conclusão: As vias de acesso anterolaterais são uma alternativa viável e segura para a osteossíntese do úmero proximal com placas bloqueadas. Nível de Evidência II, Revisão Sistemática.

Descritores: Fixação interna de fraturas, fraturas do úmero proximal, complicações, cirurgia.

Citation: Mouraria GG, Zoppi Filho A, Kikuta FK, Moratelli L, Cruz MA, Etchebehere M. Anterolateral approaches for proximal humeral osteosynthesis: A systematic review. Acta Ortop Bras. [online]. 2019;27(3):178-82. Available from URL: http://www.scielo.br/aob.

\section{INTRODUCTION}

The deltopectoral approach is commonly used for surgical treatment of proximal humerus fractures; ;,2 however, it can be difficult to expose cases of greater tuberosity fractures posteriorly deviated or cases of fractures with retroversion of the humeral head with this method. ${ }^{3}$

The anterolateral approach to proximal humerus fractures is performed between the anterior and middle portions of the deltoid. Thus, it provides better exposure of the greater tuberosity when posteriorly deviated, and also to the lateral aspect of the humerus, facilitating placement of a locking plate as the implant has a fixed angle. ${ }^{3}$
Some surgeons avoid the anterolateral approach due to the potential risk of iatrogenic injury to the anterior branch of the axillary nerve. ${ }^{4}$ This nerve can be identified during surgery either by direct visualisation (extended exposure) or by palpation through a deltoid incision, as described by the minimally invasive plate osteosynthesis (MIPO) technique.

Burkhead described the distance of the nerve to the acromion. ${ }^{5}$ Mackenzie reported an extended approach capable of exposing the anterolateral aspect of the proximal humerus safely for total shoulder arthroplasty. ${ }^{6}$ Studies of the anterolateral approach and the anatomical description of the axillary nerve have gained new popularity with the advent of locking plates. . $^{3,-9}$

All authors declare no potential conflict of interest related to this article. 
This review identifies the incidence of iatrogenic axillary nerve lesions and evaluates the clinical results of internal fixation of proximal humerus fractures treated with locking plates using anterolateral approaches.

\section{MATERIALS AND METHODS}

This review followed the PRISMA protocol. ${ }^{10}$ The search was carried out in the PUBMED, EMBASE, and Cochrane databases using the following terms (PICOS method): Patient: humerus fracture, proximal humerus fracture, shoulder fracture and related terms; Intervention: deltoid split approach, anterolateral approach, Mackenzie approach and related terms; Comparison: Deltopectoral approach (unfixed item); Outcomes: axillar nerve palsy, axillar nerve injury, functional outcomes and related terms; Study design: randomised controlled trial, observational studies.

The review was conducted in August 2016 and repeated in June 2017 to include the most recent literature. The criteria for including articles were English language, proximal humerus fracture due to trauma, description of the approach, use of a locking plate, minimum 6-month follow-up, and relevant functional results, such as functional score, range of motion, pain, or satisfaction. Studies that did not achieve all of these criteria were excluded. Studies that used an extended approach through which the skin was incised in an elliptical flap were also excluded. ${ }^{11}$ Information regarding institutions, authors, and journals was not revealed to minimise bias. The selected articles were evaluated in full by two reviewers regarding the demographic characteristics of the patients, follow-up time, type of fracture, type of approach, functional results assessed by clinical and radiographic parameters, rehabilitation protocol, and quality of the publication. The disagreements were resolved by joint review of the same reviewers. Agreement between the reviewers was assessed by Kappa statistics.

\section{RESULTS}

A total of 2,781 articles were obtained. Of these, 103 contained titles and abstracts relevant to the study and were selected for a complete reading of the text. After this stage, 24 articles (Kappa $=0.60 ; p<0.001$ ) were included, of which 1,162 patients were selected, and 831 anterolateral approaches were performed. The general characteristics of the studies are described in Table 1. There was great heterogeneity between the studies. Only two randomised clinical trials compared anterolateral to deltopectoral approaches. Mean patient age was 63.4 years, and $67 \%$ were female. In the studies that compared the anterolateral approach with the deltopectoral approach, the distributions of age and sex were homogeneous between the groups. Seven studies (303 individuals) evaluated the correspondence between the fracture side and the dominant side, and $50.3 \%$ of cases were ipsilateral.

The fractures were classified according to Neer in 14 articles, according to the OTA/AO classification in five articles, and by both Neer and OTA/AO in three. Two studies did not define the fracture classification. According to the Neer classification, fractures in two parts corresponded to $30.5 \%$, three parts to $51.0 \%$, and four parts to $18.5 \%$ of the cases. Based on the $\mathrm{AO}$ classification, type $\mathrm{A}$ fractures corresponded to $20.8 \%$, type B $45.8 \%$, and type C $33.4 \%$. No difference was observed in fracture type between the groups in studies that compared the type of approach.

The most commonly used anterolateral approach was deltoid split with MIPO, described in 18 articles (695 patients). The extended deltoid split (Mackenzie), was used in four articles (77 patients). Two studies (total, 59 patients) used both approaches depending on the type of fracture or plate size.
Table 1. General characteristics of the articles.

\begin{tabular}{|c|c|c|c|c|c|}
\hline Author & Year & $\begin{array}{l}\text { Type of } \\
\text { study }\end{array}$ & $N(* *)$ & Age & Approaches \\
\hline Sohn et al. ${ }^{12}$ & 2017 & Prospective & $90 / 45$ & 64 & $\begin{array}{c}\text { Deltoid-split (MIPO) } \\
\text { x Deltopectoral }\end{array}$ \\
\hline Buecking et al. ${ }^{13}$ & 2014 & Prospective & $90 / 48$ & $69^{*}$ & $\begin{array}{c}\text { Deltoid-split (MIPO) } \\
\text { x Deltopectoral } \\
\end{array}$ \\
\hline Fischer et al. ${ }^{14}$ & 2016 & Retro & $50 / 20$ & 59.4 & $\begin{array}{l}\text { Deltoid-split (MIPO) } \\
\text { x Deltopectoral }\end{array}$ \\
\hline Liu et al. ${ }^{15}$ & 2015 & Retro & $91 / 39$ & $60.2^{*}$ & $\begin{array}{c}\text { Deltoid-split (MIPO) } \\
\text { x Deltopectoral } \\
\end{array}$ \\
\hline Jung et al. ${ }^{16}$ & 2013 & Retro & $32 / 32$ & 72.4 & Deltoid-split (MPO) \\
\hline $\begin{array}{l}\text { Martetschläger } \\
\text { et al. }{ }^{17}\end{array}$ & 2012 & Retro & $70 / 37$ & 59 & $\begin{array}{c}\text { Deltoid-split (MIPO) } \\
\text { x Deltopectoral } \\
\end{array}$ \\
\hline Wu et al. ${ }^{18}$ & 2011 & Retro & $60 / 28$ & $58.6^{\star}$ & $\begin{array}{l}\text { Deltoid-split(MIPO)/ Extended } \\
\text { deltoid split) } x \text { Deltopectoral }\end{array}$ \\
\hline Röderer et al. ${ }^{19}$ & 2010 & Retro & $54 / 54$ & 70 & Deltoid-split (MIPO) \\
\hline Hepp et al. ${ }^{20}$ & 2008 & Retro & $83 / 39$ & 65 & $\begin{array}{c}\text { Deltoid-split (MIPO) } \\
\text { x Deltopectoral } \\
\end{array}$ \\
\hline Lin et al. ${ }^{21}$ & 2014 & Retro & $86 / 43$ & $63^{*}$ & $\begin{array}{c}\text { Deloid-split (MIPO) } \\
\text { x Deltopectoral } \\
\end{array}$ \\
\hline Falez et al. ${ }^{22}$ & 2016 & Retro & $74 / 74$ & 68.5 & Deltoid-split (MIPO) \\
\hline Chen et al. ${ }^{23}$ & 2015 & Retro & $27 / 27$ & 67.3 & Deltoid-split (MIPO) \\
\hline Koljonen et al. ${ }^{24}$ & 2015 & Retro & $40 / 40$ & 63 & Deltoid-split (MIPO) \\
\hline Bockmann et al. ${ }^{25}$ & 2015 & Retro & $52 / 52$ & 67 & Deltoid-split (MIPO) \\
\hline Oh et al. ${ }^{26}$ & 2015 & Retro & $26 / 26$ & 67 & Deltoid-split (MPO) \\
\hline Singh et al. ${ }^{27}$ & 2015 & Retro & $20 / 20$ & 45.9 & Deltoid split (MIPO) \\
\hline Imarisio et al. ${ }^{28}$ & 2013 & Retro & $29 / 29$ & 53 & Deltoid-split (MIPO) \\
\hline Barco et al..$^{29}$ & 2012 & Retro & $23 / 23$ & 62 & Deltoid-split MIPO \\
\hline Ruchholtz et al. ${ }^{30}$ & 2011 & Retro & $50 / 50$ & 65.5 & $\begin{array}{l}\text { Deltoid-split (MIPO) } x \\
\text { Extended deltoid split } \\
\end{array}$ \\
\hline Gavaskar et al. ${ }^{31}$ & 2010 & Retro & $15 / 15$ & 43 & Deltoid split (MIPO) \\
\hline Laflamme et al. ${ }^{32}$ & 2008 & Retro & $27 / 27$ & 64 & Deltoid split (MIPO) \\
\hline Gardner et al. ${ }^{33}$ & 2008 & Retro & $23 / 23$ & 65 & Extended deltoid split \\
\hline $\begin{array}{c}\text { Somasundaram } \\
\text { et al. }{ }^{34} \\
\end{array}$ & 2013 & Retro & $21 / 11$ & 64.6 & $\begin{array}{c}\text { Extended deltoid split } \\
\text { x Deltopectoral } \\
\end{array}$ \\
\hline Acklin et al. ${ }^{35}$ & 2012 & Retro & $29 / 29$ & 64 & Deltoid-split (MIPO) \\
\hline
\end{tabular}

study/individuals among whom were submitted to the anterolateral approach. Retro, retrospective.

Studies that did not expose the axillary nerve (MIPO) described a longitudinal incision starting from the lateral or anterolateral edge of the acromion, following distally by $5 \mathrm{~cm}$ or starting 1 $\mathrm{cm}$ below the acromion and following distally by up to $4 \mathrm{~cm} .^{12}$ The anterior and middle fibres of the deltoid were dissected (no more than $5 \mathrm{~cm}$ in relation to the acromion). Next, a digital scan was performed to identify the axillary nerve without visualising it. After identifying the nerve, two alternatives were observed. The first was maintenance of a skin bridge over the nerve path associated with a second $2-3-\mathrm{cm}$ distal incision, guided or not by fluoroscopy, to access the distal portion of the plate. The second was the performance of mini incisions, sufficient for the passage of a screw each, guided by fluoroscopy.

Studies that exposed the axillary nerve (extended approach) made an incision of $10 \mathrm{~cm}$ (range, $6-12 \mathrm{~cm}$ ) that began at the lateral or anterolateral edge of the acromion and followed distally parallel to the axis of the diaphysis. The anterior and middle portions of the deltoid were separated, and the axillary nerve was identified under direct and protected visualisation.

The most commonly used locking plate was the PHILOS (Proximal Humerus Internal Locking System; DePuy Synthes ) followed by NCB-PH (Non-Contact Bridging-Proximal Humerus; Zimmer ). In 
addition to osteosynthesis, one study used a bone graft, and another (autologous) used a bone substitute. ${ }^{23,34}$ Another study used the same anterolateral approach for osteosynthesis with both locking plates (14 cases) and intramedullary nails (9 cases). ${ }^{33}$

The Constant-Murley score was the most frequently used functional evaluation, (21 articles) with an average of 75.2 points in patients treated with an anterolateral approach. (Table 2) The Disabilities of the Arm, Shoulder and Hand (DASH) test was the second most used (nine articles) with an average of 16.9 in the same group. Among studies that compared the approaches, no study showed a significant difference in the functional scores between the anterolateral and the deltopectoral approaches. The anterolateral approach group showed a significantly better performance during the first postoperative month.

Three cases $(0.38 \%$ ) of iatrogenic lesions of the anterior axillary nerve branch identified by clinical criteria (18 articles) or associated with electrophysiological studies (5 articles) were confirmed. (Table 2) The main clinical criteria observed were atrophy of the anterior deltoid and loss of shoulder elevating strength.

One study compared the operated side with the contralateral healthy shoulder and observed a decrease in anterior flexion and lateral elevation, but did not attribute these deficits to axillary nerve injury. ${ }^{19}$ Another study identified the same clinical presentation in three patients, but only one had the axillary nerve lesion confirmed by electromyography. ${ }^{16}$ Hypotrophy of the anterior deltoid was identified in one case of another study, but the electromyography did not present changes. ${ }^{29}$ All confirmed cases of iatrogenic axillary nerve injury occurred during the minimally invasive approach.

Axillary nerve evaluation was the only complication described in all articles. The main complication was subacromial impingement. No other complications were uniformly evaluated and are described in Table 3.

\section{DISCUSSION}

Surgical treatment for fractures of the proximal humerus has undergone a great evolution with locking plates. The biomechanical characteristics of this implant provide better fracture stability, particularly in elderly patients and those with osteoporosis. ${ }^{36}$ Locking plates have a fixed angle and should be attached to the lateral aspect of the humerus. Thus, exposing this area is fundamental to the surgical approach. ${ }^{36}$ The deltopectoral approach does not require identifying the axillary nerve and this approach is the most performed by surgeons for proximal humerus osteosynthesis.

Mackenzie was the first to describe the extended anterolateral approach to arthroplasties; no iatrogenic lesions were detected on the axillary nerve. Gardner demonstrated the safety and efficacy of this approach in proximal humeral osteosynthesis. However, today few surgeons opt for this approach due to the potential risk to the axillary nerve. ${ }^{37}$ We have seen an increase in the number of articles that evaluated the use of the anterolateral approach, especially by MIPO.

The most commonly used anterolateral approach was the MIPO technique. All articles respected the parameters established by Burkhead for the axillary nerve safety zone. ${ }^{5}$ Use of the most distal screws of the plate should be avoided due to the risk of injury to the axillary nerve in the MIPO technique. ${ }^{4}$ However, these screws are responsible for stabilising the proximal posteromedial region of the humerus, adding biomechanical stability. ${ }^{38}$ Thus, the extended anterolateral approach with direct observation of the axillary nerve, allows use of these screws safely, leading to more stability for the osteosynthesis. Furthermore, no case of axillary nerve injury was observed in patients treated with the extended approach as observed by Mackenzie and Gardner. ${ }^{6}$ The studies were heterogeneous in the axillary nerve evaluation methods, as some performed only a clinical
Table 2. Clinical evaluation.

\begin{tabular}{|c|c|c|c|}
\hline Author & Year & $\begin{array}{l}\text { Score / Functional } \\
\text { evaluation }\end{array}$ & $\begin{array}{c}\text { Number axillary } \\
\text { palsy (evaluation } \\
\text { method) }\end{array}$ \\
\hline Sohn et al. ${ }^{12}$ & 2017 & Constant, UCLA, VAS & None (Clinical) \\
\hline Buecking et al. ${ }^{13}$ & 2014 & Constant, ADL, VAS & None (Clinical) \\
\hline Fischer et al. ${ }^{14}$ & 2016 & $\begin{array}{l}\text { Constant, DASH, } \\
\text { ASES, ROM, }\end{array}$ & None (ENMG) \\
\hline Liu et al. ${ }^{15}$ & 2015 & Constant, DASH, ROM & None (Clinical) \\
\hline Jung et al. ${ }^{16}$ & 2013 & $\begin{array}{l}\text { Constant, VAS, } \\
\text { ROM, ADL }\end{array}$ & 1 (ENMG) \\
\hline Martetschläger et al. ${ }^{17}$ & 2012 & \begin{tabular}{|l|} 
Constant, ADL, ROM, \\
ASES, DASH, Strength
\end{tabular} & None (Clinical) \\
\hline Wu et al. ${ }^{18}$ & 2011 & Constant, DASH & None (ENMG) \\
\hline Röderer et al..$^{19}$ & 2010 & Constant, ROM & None (Clinical) \\
\hline Hepp et al. ${ }^{20}$ & 2008 & Constant, DASH & None (Clinical) \\
\hline Lin et al. ${ }^{21}$ & 2014 & Constant & 1 (Clinical + ENMG) \\
\hline Falez et al. ${ }^{22}$ & 2016 & Constant & None (Clinical) \\
\hline Chen et al. ${ }^{23}$ & 2015 & Constant & None (Clinical) \\
\hline Koljonen et al. ${ }^{24}$ & 2015 & $\begin{array}{c}\text { Constant, } \\
\text { QuickDASH, ROM }\end{array}$ & None (Clinical) \\
\hline Bockmann et al. ${ }^{25}$ & 2015 & Constant, ADL, VAS & None (Clinical) \\
\hline Oh et al. ${ }^{26}$ & 2015 & $\begin{array}{l}\text { DASH, UCLA, } \\
\text { ROM, VAS }\end{array}$ & None (Clinical) \\
\hline Singh et al. ${ }^{27}$ & 2015 & Constant & None (Clinical) \\
\hline Imarisio et al. ${ }^{28}$ & 2013 & Constant & None (Clinical) \\
\hline Barco et al. ${ }^{29}$ & 2012 & Constant, DASH & None (ENMG) \\
\hline Ruchholtz et al. ${ }^{30}$ & 2011 & Constant, VAS, DASH & None (Clinical) \\
\hline Gavaskar et al. ${ }^{31}$ & 2010 & Constant, ROM & None (Clinical) \\
\hline Laflamme et al. $^{32}$ & 2008 & Constant, DASH & None (Clinical) \\
\hline Gardner et al. ${ }^{33}$ & 2008 & Quick-DASH, ROM & None (Clinical) \\
\hline Somasundaram et al. ${ }^{34}$ & 2013 & Constant, DASH & None (Clinical) \\
\hline Acklin et al. ${ }^{35}$ & 2012 & Constant & 1 (Clinical) \\
\hline
\end{tabular}

ADL score: activities of daily living; SST score: simple shoulder test; ASES score: American Shoulder and Elbow Surgeons; VAS: visual analogue scale of pain; ROM: range of motion; ENMG: electroneuromyography; DASH, the Disabilities of the Arm, Shoulder and Hand test.

Table 3. Incidence of complications.

\begin{tabular}{c|c|c|c}
\hline Complication & Variation & Average & $\begin{array}{c}\text { Number of articles that did } \\
\text { not seek complications }\end{array}$ \\
\hline Head implant loosening & $0-8 \%$ & $3.32 \%$ & 5 \\
\hline Infection & $0-8 \%$ & $1.4 \%$ & 6 \\
\hline Screw perforation & $0-12 \%$ & $2.7 \%$ & 5 \\
\hline Osteonecrosis & $0-6 \%$ & $0.8 \%$ & 0 \\
\hline Impingement & $0-25 \%$ & $4.8 \%$ & 6 \\
\hline Malreduction & $0-10 \%$ & $6.6 \%$ & 1 \\
\hline Non-union & $0-15 \%$ & $1.36 \%$ & 2 \\
\hline
\end{tabular}

evaluation, whereas others used electromyography. However, the presence of anterior hypotrophy in the deltoid did not necessarily correlate with neurological damage, and it may be assumed that a functional evaluation is more effective and predictive of outcome than electromyography.

Four-part fractures were the least prevalent. Thus, there is no way of stating whether the choice through the anterolateral approach (mainly through the MIPO technique) was prioritised in cases of less complexity. Decreased shoulder function and complications are much more frequent in patients with four-part fractures. ${ }^{12}$ The shoulders in this review were evaluated mainly by the Constant and DASH scores and showed a good postoperative function. On average, the scores were similar to those that used a deltopectoral 
approach. ${ }^{37,38}$ Most of the articles did not describe the range of motion, perhaps because its importance in postoperative patient satisfaction has not yet well been defined in the literature. ${ }^{32}$

The main complication was subacromial impingement. In some articles, it was unclear whether the impact was due to an incorrectly positioned plate or a secondary varus collapse of the head. However, one of the consequences of humeral head varus consolidation is secondary impact. Thus, if we add the patients who evolved with symptoms of impact with those who consolidated in varus, an incidence of $11.4 \%$ of complications related to the final position of the implant or reduction of the fracture was observed. This finding presupposes difficulty with fracture reduction, positioning of the plate and, adding mechanical stability to the fracture using the MIPO technique. This can occur due to a mistake of using the last proximal screws on the plate due to risk to the axillary nerve. ${ }^{32,35}$ In this case, the main strategies to avoid collapse of the varus were to tie the cuff to the plate or to place long screws near the subchondral bone, which can lead to joint perforations.

Screw perforations into the shoulder joint occurred acutely in $2.7 \%$ of cases and were related to the lack of an intraoperative observation of this complication. However, progressive migration of the screws in the articular region correlated with both varus consolidation and osteonecrosis evolution. The association between osteonecrosis with migration of the screws to the articular region causes a significant worsening of functional outcome. ${ }^{39}$
The evolution for osteonecrosis occurred on average in $<1 \%$ of patients, a smaller incidence compared with the literature, ${ }^{39}$ this could be related to a selection bias of the articles, as $85 \%$ of fractures were Neer 2 or 3 . In addition, medial comminution criteria as described by Hertel ${ }^{40}$ were not evaluated in most studies. However, an anterolateral approach, whether by the MIPO technique or extended, is less aggressive to soft tissue and may lead to a lower chance of osteonecrosis by preserving irrigation of the humeral head. ${ }^{39}$ The progression to osteonecrosis is not always associated with a worse prognosis, especially in cases of partial necrosis. ${ }^{39}$ This review had several limitations. First, only two randomised articles were identified. In addition, the studies were heterogeneous and lacked standardisation regarding the fracture classification, follow-up time, and a detailed description of the clinical evaluation method of the axillary nerve. Finally, the quality of the identified articles did not allow elaboration of the meta-analysis.

\section{CONCLUSION}

This systematic review found a low incidence of iatrogenic axillary nerve lesions and good functional outcomes in patients undergoing proximal humeral osteosynthesis treated with locking plates using an anterolateral approach by the extended deltoid split or MIPO technique. Subacromial impingement was the most frequent complication. Anterolateral approaches are an alternative for treating proximal humerus fractures.

AUTHORS' CONTRIBUTIONS: Each author contributed individually and significantly to the development of the manuscript. Main contributions: study design: GGM (0000-0002-8258-5350**, ME (0000-0002-5176-2369)*; statistical analysis: LM (0000-0002-6584-5333)*, GGM (0000-0002-8258-5350** Selection of articles and final revision: FKK (0000-0002-1409-2124) ${ }^{\star}$, AZF (0000-0002-8704-8378)*, MAC (0000-0001-9074-9186) ${ }^{\star}$, ME (0000-0002-5176$2369)^{*}, \mathrm{LM}(0000-0002-6584-5333)^{*}$, GGM (0000-0002-8258-5350**. All authors revised and approved the final version of this manuscript. *ORCID (Open Researcher and Contributor ID).

\section{REFERENCES}

1. Thanasas C, Kontakis G, Angoules A, Limb D, Giannoudis P. Treatment of proximal humerus fractures with locking plates: A systematic review. J Shoulder Elb Surg. 2009;18(6):837-44.

2. Brunner A, Thormann S, Babst R. Minimally invasive percutaneous plating of proximal humeral shaft fractures with the Proximal Humerus Internal Locking System (PHILOS). J Shoulder Elb Surg. 2012;21(8):1056-63.

3. Gardner MJ, Griffith MH, Dines JS, Briggs SM, Weiland AJ, Lorich DG. The extended anterolateral acromial approach allows minimally invasive access to the proximal humerus. Clin Orthop Relat Res. 2005:(434):123-9.

4. Apaydin N, Tubbs RS, Loukas M, Duparc F. Review of the surgical anatomy of the axillary nerve and the anatomic basis of its iatrogenic and traumatic injury. Surg Radiol Anat. 2010;32(3):193-201.

5. Burkhead WZ, Scheinberg RR, Box G. Surgical anatomy of the axillary nerve. J Shoulder Elb Surg. 1992;1(1):31-6.

6. Mackenzie D. The antero-superior exposure for total shoulder replacement. Orthop Traumatol. 1993;2(2):71-7.

7. Gardner MJ, Griffith MH, Dines JS, Lorich DG. A minimally invasive approach for plate fixation of the proximal humerus. Bull Hosp Jt Dis. 2004;62(1-2):18-23.

8. Cetik O, Uslu M, Acar HI, Comert A, Tekdemir I, Cift H. Is there a safe area for the axillary nerve in the deltoid muscle? A cadaveric study. J Bone Joint Surg Am. 2006;88(11):2395-9.

9. Smith J, Berry G, Laflamme Y, Blain-Pare E, Reindl R, Harvey E. Percutaneous insertion of a proximal humeral locking plate: An anatomic study. Injury. 2007;38(2):206-11.

10. Moher D, Liberati A, Tetzlaff J, Altman DG, Altman D, Antes G, et al. Preferred reporting items for systematic reviews and meta-analyses: The PRISMA statement. PLoS Med. 2009;6(7):e1000097.

11. Robinson CM, Khan L, Akhtar A, Whittaker R. The extended deltoid splitting approach to the proximal humerus. J Orthop Trauma. 2007;21(9):657-62.

12. Sohn HS, Jeon YS, Lee J, Shin SJ. Clinical comparison between open plating and minimally invasive plate osteosynthesis for displaced proximal humeral fractures: A prospective randomized controlled trial. Injury. 2017;48(6):1175-82.

13. Buecking B, Mohr J, Bockmann B, Zettl R, Ruchholtz S. Deltoid-split or deltopectoral approaches for the treatment of displaced proximal humeral fractures? Clin Orthop Relat Res. 2014;472(5):1576-85.

14. Fischer C, Frank M, Kunz P, Tanner M, Weber MA, Moghaddam A, et al. Dynamic contrast-enhanced ultrasound (CEUS) after open and minimally invasive locked plating of proximal humerus fractures. Injury. 2016;47(8):1725-31.

15. Liu K, Liu P, Liu R, Wu X. Advantage of minimally invasive lateral approach relative to conventional deltopectoral approach for treatment of proximal humerus fractures. Med Sci Monit . 2015;21:496-504.

16. Jung S. Indirect reduction maneuver and minimally invasive approach for displaced proximal humerus fractures in elderly patients. Clin Orthop Surg 2013:5(1):66-73.

17. Martetschläger F, Siebenlist S, Weier M, Sandmann G, Ahrens P, Braun K, et al. Plating of proximal humeral fractures. Orthopedics. 2012;35(11):e1606-12.

18. Wu CH, Ma CH, Yeh JJH, Yen CY, Yu SW, Tu YK. Locked plating for proximal humeral fractures: differences between the deltopectoral and deltoid-splitting approaches. J Trauma. 2011;71(5):1364-70.

19. Röderer G, Erhardt J, Graf M, Kinzl L, Gebhard F. Clinical results for minimally invasive locked plating of proximal humerus fractures. J Orthop Trauma. 2010;24(7):400-6.

20. Hepp P, Theopold J, Voigt C, Engel T, Josten C, Lill H. The surgical approach for locking plate osteosynthesis of displaced proximal humeral fractures influences the functional outcome. J shoulder Elb Surg. 2008;17(1):21-8.

21. Lin T, Xiao B, Ma X, Fu D, Yang S. Minimally invasive plate osteosynthesis with a locking compression plate is superior to open reduction and internal fixation in the management of the proximal humerus fractures. BMC Musculoskelet Disord. 2014;15:206.

22. Falez F, Papalia M, Greco A, Teti A, Favetti F, Panegrossi G, et al. Minimally invasive plate osteosynthesis in proximal humeral fractures: one-year results of a prospective multicenter study. Int Orthop. 2016;40(3):579-85. 
23. Chen H, Hu X, Tang H, Yang G, Xiang M. Minimal Invasive Percutaneous Osteosynthesis for Elderly Valgus Impacted Proximal Humeral Fractures with the PHILOS. Biomed Res Int. 2015;2015:971216.

24. Koljonen PA, Fang C, Lau TW, Leung F, Cheung NWK. Minimally invasive plate osteosynthesis for proximal humeral fractures. J Orthop Surg (Hong Kong). 2015;23(2):160-3.

25. Bockmann B, Buecking B, Franz D, Zettl R, Ruchholtz S, Mohr J. Mid-term results of a less-invasive locking plate fixation method for proximal humeral fractures: a prospective observational study. BMC Musculoskelet Disord. 2015;16:160.

26. Oh HK, Cho DY, Choo SK, Park JW, Park KC, Lee J II. Lessons learned from treating patients with unstable multifragmentary fractures of the proximal humerus by minimal invasive plate osteosynthesis. Arch Orthop Trauma Surg. 2015;135(2):235-42.

27. Singh H, Batra A, Patel D. Lateral transdeltoid approach to proximal humerus fractures. Int Surg J. 2015;2(3):337-40.

28. Imarisio D, Trecci A, Sabatini L, Scagnelli R. Treatment for proximal humeral fractures with percutaneous plating: Our first results. Musculoskelet Surg. 2013;97(1 Suppl):85-91.

29. Barco R, Barrientos I, Encinas C, Antuña SA. Minimally invasive poly-axial screw plating for three-part fractures of the proximal humerus. Injury. 2012;43(Suppl 2):7-11.

30. Ruchholtz S, Hauk C, Lewan U, Franz D, Kühne C, Zettl R. Minimally Invasive Polyaxial Locking Plate Fixation of Proximal Humeral Fractures: A Prospective Study. J Trauma Inj Infect Crit Care. 2011;71(6):1737-44.

31. Gavaskar AS, Muthukumar S, Chowdary N. Biological osteosynthesis of complex proximal humerus fractures: Surgical technique and results from a prospective single center trial. Arch Orthop Trauma Surg. 2010;130(5):667-72.

32. Laflamme GY, Rouleau DM, Berry GK, Beaumont PH, Reindl R, Harvey EJ. Percutaneous humeral plating of fractures of the proximal humerus: results of a prospective multicenter clinical trial. J Orthop Trauma. 2008;22(3):153-8

33. Gardner MJ, Boraiah S, Helfet DL, Lorich DG. The anterolateral acromial approach for fractures of the proximal humerus. J Orthop Trauma. 2008;22(2):132-7.

34. Somasundaram K, Huber CP, Babu V, Zadeh H. Proximal humeral fractures: The role of calcium sulphate augmentation and extended deltoid splitting approach in internal fixation using locking plates. Injury. 2013;44(4):481-7.

35. Acklin YP, Sommer C. Plate fixation of proximal humerus fractures using the minimally invasive anterolateral delta split approach. Oper Orthop Traumatol. 2012;24(1):61-73.

36. Ring D. Current concepts in plate and screw fixation of osteoporotic proximal humerus fractures. Injury. 2007;38(Suppl 3):S59-68.

37. Sproul RC, lyengar JJ, Devcic Z, Feeley BT. A systematic review of locking plate fixation of proximal humerus fractures. Injury. 2011;42(4):408-13.

38. Beeres FJP, Hallensleben NDL, Rhemrev SJ, Goslings JC, Oehme F, Meylaerts SAG, et al. Plate fixation of the proximal humerus: an international multicentre comparative study of postoperative complications. Arch Orthop Trauma Surg. 2017;137(12):1685-92

39. Boesmueller S, Wech M, Gregori M, Domaszewski F, Bukaty A, Fialka C, et al. Risk factors for humeral head necrosis and non-union after plating in proxima humeral fractures. Injury. 2016;47(2):350-5.

40. Hertel R, Hempfing A, Stiehler M, Leunig M. Predictors of humeral head ischemia after intracapsular fracture of the proximal humerus. J Shoulder Elb Surg. 2004; 13(4):427-33. 